\title{
Formação docente crítica em torno das questões de raça, etnia, gênero e sexualidade à luz da concepção de educação libertadora de Paulo Freire ${ }^{1}$
}

\section{Critical teacher education around the issues of race, ethnicity, gender, and sexuality in the light of Paulo Freire's concept of liberating education}

\author{
Juliana Rezende Torres* \\ Lourdes de Fátima Bezerra Carril ${ }^{*}$
}

\begin{abstract}
RESUMO
A formação docente, com base na educação libertadora de Paulo Freire, ocorreu com alunos de licenciatura de três cursos de uma universidade pública federal. Os processos formativos iniciais desencadearam parcerias entre a universidade e instituições do entorno (escola pública estadual e quilombo). Nessas parcerias, destaca-se o desenvolvimento de práticas educativas freireanas resultantes da emergência de situações-limite em torno das questões de raça, etnia, gênero e sexualidade mediante investigação temática. Essas situações expressam contradições sociais locais/globais, sintetizadas em temas geradores e carregam o potencial de humanização via atos-limite, aqui considerados como elaboração e desenvolvimento de currículos críticos por meio dos temas geradores. Esta pesquisa explicita situações-limite relativas à questão das diferenças e apresenta atos-limite desenvolvidos nos processos formativos freireanos junto a educandas(os),
\end{abstract}

1 Parte da pesquisa teve financiamento da Coordenação de Aperfeiçoamento de Pessoal de Nível Superior (CAPES), àquela desenvolvida no âmbito do Programa Institucional de Bolsas de Iniciação à Docência ( PIBID).

* Universidade Federal de São Carlos. Programa de Pós-Graduação em Educação. Sorocaba, São Paulo, Brasil. E-mail: julianart@ufscar.br - https://orcid.org/0000-0002-4598-6702 E-mail: lourdescarril@ufscar.br - https://orcid.org/0000-0001-9054-6880. 
para a superação de visões de mundo acríticas. A metodologia utilizada está ancorada nos pressupostos da pesquisa qualitativa em educação, pois envolve não apenas a pesquisa-ação para a realização dos processos formativos, mas também a coleta de dados da análise documental, cujos documentos utilizados foram os relatórios finais/portfólios de estudantes em licenciatura. Os principais resultados do trabalho acenam para o potencial crítico-libertador da pedagogia freireana desenvolvida em contextos de formação inicial, tendo em vista a superação de situações-limite por atoslimite, bem como para a importância do trabalho pedagógico em torno de questões relativas às diferenças, no âmbito de uma concepção de educação que visa à humanização e a democracia.

Palavras-chave: Formação inicial. Situação-limite. Ato-limite. Educação libertadora.

\begin{abstract}
The teachers' training occurred with undergraduate students from three courses at a Public University, based on the liberating education concept by Paulo Freire. The initial training process led to partnerships between this University and surrounding institutions (public school and "quilombo"). Notably, the development of educational practices based on Freire is a result of the emergence of limit-situations concerning the matters of race, ethnicity, gender, and sexuality through thematic investigations. These express local/global social contradictions synthesized in generating themes, at the same time, they are carrying humanization potential via limit-acts, herein understood as the elaboration and development of critical curricula through generating themes. This research explains limit-situations in the lens of diversity and presents limit-acts developed in the educational processes based on Freire, together with the students, to overcome non-critical world views. The methodology undertaken is anchored by the assumptions of the qualitative research in education as it involves action-research to promote educational processes and for the data collection used in the documentation analysis: the students' final reports and portfolios. The main results of this research hint at the critical-liberating potential in Freire's pedagogy as developed in the context of the initial formation employing limit-acts. Additionally, the results stress the importance of pedagogical activity concerning diversity, in the scope of an educational concept that addresses humanization and democracy.
\end{abstract}

Keywords: Initial education. Limit-situation. Limit-act. Liberating education. 


\section{Introdução}

Devemos estar engajados na ação política contra o racismo, contra o sexismo, contra o capitalismo, e contra as estruturas desumanas de produção (FREIRE; SHOR, 1986, p. 199).

Este artigo busca contribuir aos debates envolvendo a articulação entre educação, democracia e diferença, a partir da perspectiva crítica da formação inicial de professores, tendo em vista a atuação de futuras e futuros docentes na sociedade contemporânea. Nesse contexto, a questão das diferenças tem tomado corpo teórico e político na academia, nas ruas, nas escolas, nos coletivos, partidos políticos e movimentos sociais. Essa mudança de comportamento está pautada na reivindicação de reconhecimento das singularidades presentes nas sociedades atuais e é inerente aos contextos do capitalismo tardio. A questão da diferença e da identidade, em suas formulações teórico-práticas, interpela a ampliação do entendimento de paradigmas que tocam a questão da cidadania e da justiça, tornando-se importante buscar práticas docentes formativas a partir desse cenário.

Após a Segunda Guerra Mundial (1939-1945), os teóricos da Escola de Frankfurt apresentaram um diagnóstico de que a estrutura do capitalismo mudou tanto que os modos de opressão passaram a operar de maneiras diferentes. A razão instrumentalizada em benefício do sistema aprofunda a alienação dos sujeitos e os torna reprodutores das ideologias (no sentido marxiano, como manipulação da realidade). Esse diagnóstico da perda do papel histórico do operariado é acompanhado da emergência de sujeitos que se apresentam em diversos movimentos de contracultura: antibélicos; ambientalistas; antiimperialistas; feministas; de libertação das sexualidades; e dos movimentos negros. Esses sujeitos históricos se apresentam, assim, sob diversos discursos da particularização das diferenças, reivindicando o reconhecimento social e a justiça social (HONNETH, 2003).

Nesse contexto, ressaltamos a importância do trabalho educativo e democrático em torno de questões relativas às diferenças que, em uma perspectiva educacional freireana (FREIRE, 1987), podem ser tomadas como contradições sociais/situações-limite que expressam visões de mundo limitantes/ acríticas. A superação dessas visões acríticas requer o desenvolvimento de atos-limite como potencialidades de construção de uma nova forma de ver/ compreender tais questões. Neste trabalho, destacamos como situações-limite as 
questões que interseccionam raça, etnia, gênero e sexualidade em sala de aula, e como atos-limite as práticas curriculares e pedagógicas que foram desenvolvidas com os educandos. Assim, este trabalho se faz relevante socialmente por refletir e construir com os licenciandos práticas curriculares e pedagógicas críticas e democráticas que se destinam à docência junto à Educação Básica, cujo horizonte vislumbra a perspectiva de emancipação, sem a qual não há liberdade, o que aponta sua centralidade para a questão do ser mais no mundo.

Mas como pensar a liberdade sabendo-se que nas sociedades multirraciais, como a brasileira, as relações sociais são marcadas, principalmente, pela desigualdade que oprime os diferentes sujeitos, entre eles, os grupos étnicos e de diversidade de gênero e sexual? Em que medida é possível a superação de situações-limite em uma perspectiva de educação libertadora a favor da diferença e da democracia?

Por isso, neste trabalho, o objetivo é identificar e explicitar situações-limite e atos-limite a partir de processos formativos freireanos desenvolvidos com licenciandas(os) na relação universidade-instituição parceira, pautados pelas questões relativas às diferenças, na direção da humanização e democratização da educação crítica.

\section{Educação Libertadora, humanização e democracia frente às Políticas da Diferença}

Freire (1987) em sua obra Pedagogia do Oprimido denuncia a concepção de educação bancária pautada na contradição educadores/educandos(as) e na transmissão de conhecimentos universais sistematizados, como se estudantes fossem recipientes passivos. Neste contexto, Freire advoga em favor de uma educação libertadora pautada na relação horizontal, via diálogo entre saberes, problematização de conhecimentos ingênuos/acríticos, contextualização da realidade imediata/mediata, conscientização, humanização e democracia. Essa concepção de educação anuncia a libertação dos oprimidos na busca do ser mais via a identificação de situações-limite que implicam em atos-limite na direção do inédito viável - o que perpassa pelo trabalho com os temas geradores e seus respectivos temas opostos, para a elaboração de conteúdos programáticos interdisciplinares a serem trabalhados em processos formativos educativos, visando à conscientização e humanização dos educandos. "Daí que, ao nível da 'consciência real' [conhecimento ingênuo/acrítico], os homens [e as mulheres] se encontrem limitados na possibilidade de perceber mais além das 
‘situações-limites', o que chamamos de 'inédito viável'” (FREIRE, 1987, p. 107). Assim, temos que a educação se configura como meio para a transformação da realidade concreta, em suas dimensões cultural, social e material.

Freire (1987, p. 51), com base em Álvaro Vieira Pinto, considera que as situações-limite "não são o contorno infranqueável onde terminam as possibilidades, mas a margem real onde começam todas as possibilidades"; os limites não são "a fronteira entre o ser e o nada, mas a fronteira entre o ser e o ser mais". Para Freire, as situações-limite são dimensões históricas e concretas de uma dada realidade, que desafiam os sujeitos históricos, os quais incidem sobre elas ações que se dirigem à superação e à negação do dado - ao que Álvaro Vieira Pinto denomina atos-limite. Assim, para Freire, esta é a razão pela qual as situações-limite em si mesmas não são geradoras de um clima de desesperança, mas as percepções que os sujeitos têm delas em um dado momento histórico. Daí que, para ele (1987, p. 51-52), "no momento em que a percepção crítica se instaura na ação mesma [conscientização], se desenvolve um clima de esperança e confiança que leva os homens a empenhar-se (sic) na superação das situações-limites", em busca de sua humanização, em busca do ser mais. Assim, essa superação não se dá fora das relações homens-mundo e, portanto, ocorre mediante ação dos homens sobre a realidade concreta, em que se dão as situações-limite. "Superadas estas, com a transformação da realidade, novas [situações] surgirão, provocando novos atos-limites, dos homens".

Para a superação das situações-limite via atos-limite, Freire (1987) propõe o trabalho a partir dos temas geradores e seus respectivos temas opostos, que se encontra no capítulo três da referida obra, ao que ele denomina processo de Investigação Temática, para a efetivação de sua concepção de educação libertadora. Assim, é possível caracterizar sua linha de ação cultural para a libertação, a partir de momentos que estão interligados entre si e que foram sistematizados por Delizoicov, Angotti, Pernambuco (2002) e Silva, A. (2004), para o contexto escolar via a dinâmica de Abordagem Temática Freireana (ATF). Destaca-se aí, para além de uma concepção de educação progressista, concepções de currículo crítico, sujeito histórico, realidade concreta e histórica, ciência como construção humana e histórica, conhecimento como construção social e voltado à humanização.

A dinâmica de ATF assim se configura: Primeira etapa (levantamento preliminar): consiste em reconhecer o ambiente em que vive a(o) educanda(o), seu meio, seu contexto. Segunda etapa (análise das situações e escolha das codificações): momento em que é realizada a escolha de situações-limite que sintetizam as contradições sociais vividas/percebidas. Terceira etapa (diálogos descodificadores): a partir desses diálogos se obtêm os Temas Geradores e seus respectivos temas opostos - contratemas. Quarta etapa (redução temática): 
consiste em um trabalho de equipe interdisciplinar, com o objetivo de elaborar os conteúdos programáticos e identificar quais conhecimentos disciplinares são necessários para o entendimento dos temas. Quinta etapa (trabalho em sala de aula): desenvolvimento do programa em sala de aula a partir dos temas geradores e contratemas.

Aqui, com base em processos formativos críticos viabilizados mediante parceria entre universidade e instituições do entorno, traremos à tona situações-limite que expressam contradições sociais em torno de questões relativas à diferença, sua abordagem em torno de temas geradores e contratemas que envolve a elaboração de currículos críticos e a efetivação das práticas pedagógicas daí decorrentes - os possíveis atos-limite, o inédito viável.

A partir desta premissa denúncia da estrutura desumanizante e anúncio da estrutura humanizadora é que situamos a importância e pertinência da concepção educacional libertadora para o enfrentamento de situações-limite em torno de questões relativas à raça, etnia, gênero e sexualidade, como exemplos de situações que envolvem as lutas pela diferença.

$\mathrm{O}$ questionamento do modelo binário, fundado na generificação e colorização dos corpos, bem como na normalização da sexualidade, tem se tornado o núcleo central da crítica social no mundo contemporâneo. Na medida em que a tendência à expansão do sistema mundo se constituiu mais efetivamente e uma cultura global se estabeleceu homogeneizando os lugares e os sujeitos, acirraram-se as diferenças. Essa diversidade de identidades, ao se expressar politicamente confronta as classificações sociais e as estruturas de poder que a produz. Nesse contexto, pensar as práticas pedagógicas libertadoras requer a análise das contradições sociais trazidas à sala de aula, as quais se imbricam, muitas vezes, à dialética entre o reconhecimento da diversidade social e as lutas pelos direitos universais.

As lutas pela diferença se vinculam ao contexto das mudanças sociais ocorridas, principalmente na segunda metade do século XX, com os movimentos de maio de 1968. A partir dos países centrais da economia, sob a égide do Estado de Bem-estar Social, novos sujeitos se autoafirmam com base nas diferenças e nas singularidades. Essas rupturas com o instituído trouxeram mudanças nas noções filosóficas que embasaram a existência de um sujeito fixo, questionando as organizações sociais e suas formas definidoras de papéis, em relação à produção de sujeitos generificados, nas suas determinações culturais pelas divisões de papéis dentro da família, do mercado e da política. Segundo Hall (2006, p. 35), esse processo se insere nas críticas diversas ao sujeito do Iluminismo "centrado, unificado, dotado das capacidades de razão, de consciência e de ação", ou seja, esse deslocamento se dá através de uma série de rupturas também com os discursos do conhecimento moderno. 
Como foi assinalado pela teoria crítica (ADORNO; HORKHEIMER, 1985), a inclusão de amplas massas ao mercado de consumo contribuiu para que outras estruturas da sociedade passassem a ser questionadas, acarretando uma espécie de democratização do capitalismo; inclusive, uma ilusão graças às desigualdades cada vez maiores, a partir da crise capitalista e da ascensão das políticas neoliberais. Nesse sentido, a teoria propiciou refletir criticamente a produção de objetos a serem consumidos na lógica fordista e taylorista, bem como o modelo que estabeleceu, também, formas de vida pautadas na lógica racional do consumo, coerentes com a ideia de um "capitalismo administrado". Essa lógica de organização da vida avançou, ao longo do século XX e XXI, sob o signo da flexibilização e do capitalismo hedonista, do fetichismo do mercado e da mercadoria, do imediatismo e da lógica do prazer momentâneo que, ao ser estendido para esferas amplas da vida social, acomete, inclusive, as subjetividades, logrando construí-las como falsas identidades.

Segundo Safatle (2015), a questão da diferença contribuiu para a consolidação do esvaziamento do papel histórico do proletariado, mas, ao mesmo tempo, fortaleceram-se as lutas de valorização por autorrealização e reparação aos prejuízos causados pela imposição normativa hegemônica que prejudicava as alteridades. Analisando as vertentes teóricas que produzem o debate entre justiça redistributiva e políticas de afirmação, Safatle $(2015$, p. 82$)$ analisa que, com "esse deslocamento da espoliação à inautenticidade no interior da crítica ao trabalho, abria-se mais uma porta para secundarizar o conceito de luta de classes e elevar o problema do reconhecimento a dispositivo político central".

É possível analisar posições dissimétricas, também, entre as subjetividades e sua posição demandante de atenção política entre os grupos (HIRATA, 2015). Ou seja, os sujeitos, ao se fecharem em identidades próprias, podem vir a desconsiderar outras perspectivas da diferença, e, ao mesmo tempo, se descolarem das relações de classe. Entendemos as diferenças a partir das interseccionalidades, posto que é a interação entre os marcadores sociais e culturais, o que nos ajuda a localizar os pontos da intersecção das diferenciações que colocam o sujeito na posição de marginalidade social. Esse conceito tem sido sistematizado por Crenshaw (2002, p. 177) como: "uma conceituação do problema que busca capturar as consequências estruturais e dinâmicas da interação entre dois ou mais eixos da subordinação. Ela trata, especificamente, da forma pela qual o racismo, o patriarcalismo, a opressão de classe e outros sistemas discriminatórios criam desigualdades básicas que estruturam as posições relativas de mulheres, raças, etnias, classes e outras”. 
É a partir do jogo das diferenças que surgem as identidades, no interior das relações de força e da biopolítica do poder (FOUCAULT, 2008). Para Foucault, a partir do século XVIII, o Ocidente conheceu uma profunda transformação nos mecanismos de poder. O poder de soberania, o direito de causar a morte ou de deixar viver tão característico desse poder, é agora substituído por "um poder que gera a vida e a faz se ordenar em função de seus reclamos" (FOUCAULT, 1988, p. 128). A diferença seria, então, um conjunto de princípios organizadores da seleção, inclusão e exclusão que informam o modo como indivíduos marginalizados são posicionados na estrutura de poder e construídos em teorias sociais dominantes, práticas sociais e agendas políticas.

A política da diferença vai tratar, assim, de organizar os anseios de grupos subalternos com base na eticidade e na moral social (HONNETH, 2003), com vistas à resolução dos conflitos advindos das pretensões normativas estruturalmente inscritas que acarretam lesões nas subjetividades e na reprodução da vida, bem como no vir a ser dos sujeitos. Nesse sentido, a identidade e diferença não poderiam ser compreendidas fora do sistema de significação no qual adquirem sentido, uma vez que tanto uma quanto a outra fazem parte de discursos que se estabilizam por serem utilizados e vividos no cotidiano, demandando, assim, defesa ao ordenamento jurídico e práticas educativas que visam à emancipação dos indivíduos (SILVA, T., 2004).

No Brasil, a Constituição Brasileira de 1988 abarca a diversidade étnica e o pluralismo cultural, embora não reconheça explicitamente as diversas singularidades manifestadas na sociedade. Num país em que as dívidas históricas permanecem na cena social, fruto das formas capitalistas periféricas e do longo período da escravidão, da qual os sujeitos saíram sem suportes e amparo necessários à inserção social, as lutas se diversificam em torno da busca de direitos e de sua garantia constitucional. O símbolo maior de nossa cultura de cidadania tornou-se a democracia racial engendrada pelas elites no transcurso da escravidão para a sociedade livre. Na construção da sociedade brasileira, fez-se valer o ideal do branqueamento como ideologia para a manutenção das grandes desigualdades produzidas pelo capitalismo, tendo como fundamento a eugenia, que será praticada quase como redenção do mal de origem.

O Artigo 68 do Ato das Disposições Constitucionais Transitórias, da Constituição Federal de 1988 - ADCT (BRASIL, 1988) veio a reconhecer, um século após a abolição, o direito à titulação dos territórios quilombolas, sendo preciso pensar sobre as diferentes formas de usos do território, no campo e na cidade. Nesse processo, passou-se a analisar como, no presente, as pessoas se veem e como elas se identificam. A vida delas não é uma reminiscência do passado, mas a compreensão dos limites históricos que pesam no exercício da 
cidadania para uma grande parcela da sociedade brasileira. O Decreto 4887/2003 (BRASIL, 2003) veio a regulamentar o procedimento para identificação, reconhecimento, delimitação, demarcação e titulação dos territórios quilombolas, estabelecendo o critério da autodefinição dos povos tribais e indígenas, com base na consciência de sua própria identidade.

Assim, pensar paradigmas pedagógicos que venham modificar o modelo educacional vigente no Brasil, marcadamente impregnado pela estrutura social racista e eurocêntrica, é fundamental. Nela, a colonização das mentes produz o desejo de alcance do padrão ocidental e branco, os ideais de Ego do sujeito branco dominantes, levando à recusa, negação e anulação do corpo negro (COSTA, 1990). A desconsideração das experiências sociais dos sujeitos invisibiliza, assim, comunidades étnicas, sujeitos marcados pela cor da pele, pobres, faveladas(os), mulheres e LGBTQIA $+^{2}$ inviabilizando a autoafirmação como sujeitos de direitos.

No que se refere às questões de gênero e sexualidade, Rocha (2009) sinaliza que $46 \%$ da população trans no Brasil não finalizou o Ensino Fundamental. Estudantes que não se adequam ao padrão da heteronormatividade acabam por sofrer silenciamento, dominação simbólica, controle e vigilância, o que explica a interrupção da trajetória escolar devido à violência de gênero e sexual. Para Hooks (2013), se o pensamento retrógrado impera nas escolas, trata-se de uma exigência pedagógica enfrentar as forças das opressões racistas, sexistas e homotransfóbicas que tendem a dominar o ambiente escolar - considerando que o Brasil está no topo do ranking de assassinatos de pessoas trans no mundo (BENEVIDES; NOGUEIRA, 2019).

\section{Percursos metodológicos da pesquisa}

Em se tratando de pesquisas cuja intencionalidade ultrapassa dados quantitativos e busca informações contidas na subjetividade do processo educativo, é imperativo que a organização sistemática da investigação seja qualitativa. Assim, a elaboração deste trabalho fundamentou-se na pesquisa qualitativa em educação a partir da análise documental (LÜDKE; ANDRÉ, 1986).

2 Lésbicas, gays, bissexuais, transgêneros (inclui travestis), queers, intersexuais, assexuais, + (simpatizantes). 
A pesquisa qualitativa em Educação é aquela que se volta aos aspectos qualitativos de determinadas questões educacionais, sendo analisadas subjetividades, percepções e comportamentos, que correspondem às concepções de mundo específicas e à compreensão da realidade. Lüdke e André (1986) nomeiam como principal característica dessa abordagem metodológica a preocupação com o processo maior do que com o produto. O procedimento da pesquisa, a maneira pela qual os eventos se desenvolvem, detém a maior atenção do processo de desenvolvimento do trabalho. A realidade e concepção das coisas e da vida que as(os) participantes possuem são de suma importância para a contextualização da pesquisa, permitindo explorar por diferentes visões e perspectivas, a situação investigada. A partir disso, a análise do que foi coletado gera um processo de formulação das hipóteses ao longo da investigação.

Triviños (1987) define dois enfoques para a pesquisa qualitativa, um fenomenológico e outro marxista. Aqui utilizaremos o enfoque fenomenológico como método de coleta de dados (falas significativas ${ }^{3}$ de educandas(os) que expressem contradições sociais/situações-limite). Já o enfoque marxista, como metodologia de pesquisa para análise dos dados. Neste contexto, nosso olhar analítico é de viés crítico-participativo com base na dimensão histórico-estrutural-dialética da realidade social, pois parte da necessidade de incutir nos educandos a necessidade de transformar a realidade em processos contextuais e dinâmicos complexos, ao conhecer a realidade através de percepções, reflexão e intuição. Assim, a pesquisa qualitativa desvela questionamentos que contribuem significativamente para a compreensão dos fenômenos educativos, decorrentes do cotidiano escolar e seus contextos.

No mais, a pesquisa qualitativa é adequada já que rompe com a neutralidade dos modelos científicos positivistas usados em pesquisas quantitativas, pois superam esses modelos pela inserção de investigações que consideram contextos e processos socioculturais, comprometidos com a transformação da realidade e emancipação dos sujeitos (CHIZZOTTI, 2003).

Segundo Caulley (1981) apud Lüdke e André (1986), a análise documental busca identificar informações factuais nos documentos a partir de questões ou hipóteses de interesse. A importância de pesquisas que utilizam documentos como fontes de dados reside no fato de estes representarem fontes estáveis e ricas, que persistem ao longo do tempo e podem ser consultados ou servirem de base para outros estudos que se aproximam do problema de pesquisa em questão.

3 Expressam visões de mundo limitantes (limites explicativos) em torno de situações-limite advindas da realidade concreta (SILVA, A. 2004). 
Para esta pesquisa são utilizadas como fontes documentais os relatórios finais/portfólios das(dos) licenciandas(os) em Biologia (semestre 2017.2), provenientes de suas vivências junto ao Programa Institucional de Bolsas de Iniciação à Docência da Coordenação de Aperfeiçoamento de Pessoal de Nível Superior (PIBID/CAPES); os relatórios finais dos licenciandos em Geografia (semestre 2016.2), oriundos da disciplina de Estágio Curricular Supervisionado, e os relatórios finais dos licenciandos em Pedagogia (semestre 2016.1), relativos à disciplina Metodologia e Prática de Ensino de Geografia e História.

Para tanto, nosso objeto de estudo, como docentes formadoras do ensino superior são as práticas educativas desenvolvidas na relação parceria Universidade-instituições do entorno, tendo em vista identificar falas significativas dos educandos que expressem situações-limite/contradições sociais em torno das questões da diferença. Para esse trabalho, focamos nas situações-limite relativas à raça, etnia, gênero e sexualidade.

Foram duas as parcerias estabelecidas entre a universidade e instituições: uma entre a Universidade Federal de São Carlos campus Sorocaba e uma escola pública estadual via PIBID e outra entre a mesma Universidade e o Quilombo Cafundó. Ambas as instituições parceiras se situam no município de Salto de Pirapora - SP. A escola em questão foi escolhida visando à melhoria da educação básica mediante o desenvolvimento de processos formativos críticos pela coordenação de área (docente do ensino superior) junto aos(as) licenciandos(as) e supervisores(as) (professores/as da escola) para suas atuações em sala de aula. O Quilombo Cafundó foi escolhido por se tratar de comunidade próxima e parceira de nossas pesquisas e projetos de ensino crítico.

Nossa hipótese inicial é que as(os) estudantes apresentam visões de mundo ingênuas ou acríticas (situações-limite) acerca das questões de raça, etnia, gênero e sexualidade.

\section{Experiências pedagógicas a partir da análise de situações-limite}

Abaixo traremos recortes/excertos de falas que expressam situaçõeslimites/contradições sociais e possam ser analisadas à luz da concepção de educação libertadora de Paulo Freire, o que perpassa pela sua linha de ação cultural para a libertação dos oprimidos. 


\section{Situações-limite e atos-limite em torno de questões sobre diversidade e desigualdade de gênero e sexual}

As situações-limite aqui apresentadas foram retiradas do relatório final do $\mathrm{PIBID}^{4}$, de três licenciandas(os) em Biologia a partir do processo formativo desenvolvido no momento Universidade (coordenação de área, supervisores, licenciandos/as) e desenvolvido em parceria com supervisores(as) no momento escola. Tais situações-limite giram em torno de questões referentes à diversidade e desigualdade de gênero e sexual, e emergiram de uma pesquisa sociocultural (diagnóstico inicial), conforme indicações de Silva A. (2004), desencadeada pela/os licenciandas(os) junto a estudantes da educação básica, a partir das seguintes questões: 1) Descreva uma situação ou o que te faz feliz e triste; 2) Você pode descrever em poucas palavras como é o bairro em que você mora? O que você mais gosta dele? O que você não gosta e acha que poderia ser diferente? 3) Como você se imagina futuramente? e 4) O que você faz durante o seu dia? O que você mais gosta e menos gosta nele? A partir daí surgiram um conjunto de falas das(dos) educandas(os) (SILVA A., 2004) que trouxeram à tona, o que Freire (1987) aponta como hipóteses de situações-limite em torno: de situações de tédio por falta de lazer/ocupação do tempo; das formas desiguais de acesso às diferentes mídias digitais; da escola como lócus de prazer, desprazer/obrigação; de realização de tarefas domésticas como responsabilidade das meninas; do machismo como situação dada e do castigo como meio de repressão. Dessas hipóteses de situações-limite que surgiram no âmbito das falas foram legitimadas, como sendo representativas do coletivo dos educandos investigados, as situações em torno da diversidade e desigualdade de gênero e sexual, conforme aponta Crenshaw (2002), buscando trabalhar as diferenças a partir das interseccionalidades, o que se encontra expresso nas seguintes falas significativas trazidas pelos educandos da Educação Básica:

1) "Homem quer ser mulher e mulher quer ser homem". 2) "Deixei de jogar bola/brincar de boneca/deixar o cabelo crescer...por ser menino/ menina. Mas não existe diferença entre mulheres e homens". 3) "Exemplo de machismo é quando o homem vira mulher e a mulher vira homem".

4 Relatório de Atividades do Programa Institucional de Bolsa de Iniciação à Docência Subprojeto: Biologia, realizado pelos bolsitas Elisha Silva de Jesus, Laura Alves de Oliveira e Leonardo Oliveira da Costa, UFSCar Sorocaba, 2017. 
4) "Meninos não pintam a unha e meninas pintam". 5) "A mulher que sabe cuidar da criança". 6) "O homem é mais forte do que a mulher por isso pode fazer trabalhos pesados". 7) "A mulher ajuda os homens nos afazeres domésticos e os homens ajudam as mulheres pagando as contas". 8) "O homem quer ser mais que a mulher". 9) "Exemplo de comportamento machista é ilusão". 10) "Existe diferença entre homens e mulheres, porque homem tem pênis e mulher tem vagina".

Situações-limite: Essas podem ser analisadas mediante falas que apresentam contradições sociais na medida em que naturalizam diferenças e desigualdades sociais partindo de parâmetros biológicos. Há culpabilização das pessoas que desviam dos estereótipos de gênero (pautados na genitália) pela opressão que sofrem e pelo machismo. $\mathrm{O}$ entendimento freireano de situação-limite vai ao encontro da ideia de Hirata (2015) de que é possível analisar posições dissimétricas, também, entre as subjetividades ressaltando posições demandantes de atenção política entre os grupos. Tema gerador (visão de mundo dos(as) educandos(as) expressa na fala): "Existe diferença entre homens e mulheres, porque homem tem pênis e mulher tem vagina". Contratema (visão de mundo dos/as educadores/as): O sexo (biológico) é o conjunto de características estruturais e funcionais segundo as quais um ser vivo é classificado como macho ou fêmea. $\mathrm{O}$ gênero (social), por sua vez, se refere à composição da identidade baseada em diversos fatores que se inter-relacionam de forma complexa, sendo ao mesmo tempo uma imposição sociocultural e uma construção subjetiva de cada sujeito. Interpretando o gênero como constructo social e não uma designação biológica, é possível entender que existem "homens com vagina" e "mulheres com pênis". As desigualdades sociais entre os gêneros não são explicadas pela diferença morfológica dos genitais, mas sim por serem as relações de gênero, relações de poder e dominação. A formulação desse contratema encontra sintonia com as ideias de Foucault (2008) relativas ao jogo das diferenças em que surgem as identidades, no interior das relações de força e da biopolítica do poder, bem como com as ideias de Honneth (2003) em torno dos sujeitos históricos sob diversos discursos da particularização das diferenças, reivindicando o reconhecimento e a justiça social. Conteúdos programáticos escolares (trabalho de equipe docente): Determinismo biológico; Genética; Cromossomos sexuais; Hormônios; Sexo biológico; Diversidade sexual no reino animal. Objetivos: Mostrar não apenas a complexidade da construção das identidades, com influências multifacetadas, genéticas e sociais, mas também o modo como a carga social se construiu através de influências econômicas, políticas e sociais (mídia/instituições familiares/políticas), tornando o sistema 
binário de gênero hetero-cis-normativo. Seguem as práticas pedagógicas desenvolvidas (atos-limite) com os educandos da educação básica, a partir do tema gerador e tema oposto, cujos fundamentos dessa dinâmica estão pautados em Freire (1987), Delizoicov, Angotti, Pernambuco (2002) e Silva A. (2004).

Ato-limite 1: Jogo dos privilégios. O jogo consistia em organizar os alunos em uma linha reta horizontal, e conforme um dos(as) licenciandos(as) ditava dados estatísticos da população brasileira, os(as) alunos(as) davam um passo à frente ou um passo atrás, conforme se identificavam com as informações. Dessa forma, todos começaram na mesma linha, pois, segundo a Constituição Brasileira "todos somos iguais perante a lei", porém, conforme o jogo trazia dados sobre questões de gênero, raça, classe, as(os) alunas(os) se movimentavam, criando no final do jogo um cenário de desigualdade: os garotos estavam à frente, enquanto todas as garotas estavam atrás. Aconteceu uma análise e discussão coletiva sobre aquele cenário em torno de questões, como religião, machismo, assédio, respeito, preconceito, transexualidade e sexo biológico. O jogo demonstrou como a injustiça social produz e reproduz desigualdades, bem como ela é mascarada como uma justiça meritocrática.

Ato-limite 2: Sexo biológico - Intersexualidade. Foi apresentada às(aos) estudantes (grupos de três) uma imagem que apresenta diferentes morfologias de órgão genital feminino/masculino/intersexual e algumas perguntas orientadoras: O que é sexo biológico? O que define o sexo biológico? O que é gênero? O que define o gênero? Quem define o gênero e o sexo biológico das pessoas? Na sua opinião existe alguma diferença entre gênero e sexo biológico? O que é órgão sexual? O que é natural? O que é normal? Tudo que é comum é natural? Após a discussão nos grupos, foi realizada uma conversa com a sala toda, em que foram apresentadas perguntas e dúvidas, assim como as(os) licenciandas(os) também fizeram perguntas a eles. De forma breve e introdutória, alguns conceitos foram abordados: sexo biológico, cromossomos sexuais, código genético, cariótipo, hormônios sexuais, hermafroditismo e intersexualidade.

\section{Ato-limite 3: Estereótipos de gênero e construção sociocultural do} gênero. Foi exibido um curta de animação produzido pela Organização das Nações Unidas, chamado "O sonho impossível?", que aborda de maneira codificada as funções sociais do homem e da mulher e a desigualdade inerente da relação de poder entre os gêneros. Provocados pelo curta, as(os) estudantes responderam às seguintes perguntas: Qual o assunto do filme, o que te faz achar isso? Quais as diferenças entre a realidade e o sonho? O filme te provocou algum sentimento ou reflexão? Qual? Enquanto assistia o filme você lembrou de alguma situação que já vivenciou? Qual? Na sua opinião qual seria o sonho impossível? Foi produzido e entregue aos(às) estudantes um texto com o título: "A biologia e a desigualdade entre gêneros", que traz uma diferenciação 
entre sexo biológico/gênero e discorre sobre como o discurso biologizante é utilizado para naturalizar desigualdades entre os gêneros. A partir do texto, o grupo de estudantes foi incentivado a escrever as palavras cujo significado desconheciam, para então iniciar uma discussão coletiva sobre o assunto. Foi-lhes solicitado que respondessem em uma folha à parte e sem nome uma reflexão sobre o texto e a imagem.

Ato-limite 4: Expressão de gênero e transexualidade. Foi apresentado um slide sobre como os diferentes gêneros são expressos em diferentes culturas, e trazidos exemplares de expressões de gênero pouco típicas, como homem de cabelo comprido, mulher careca, saia masculina, dentre outras expressões. Foi introduzido o conceito de androginia, mostrando exemplos de pessoas não binárias. Outros dois conceitos que foram trabalhados foram cis e trans. Também foi apresentado um vídeo da Rosa (2018) uma mulher transgênero que produz vídeos para o seu canal no Youtube chamado Barraco da Rosa, que explica o que são os conceitos trans e cis e o que seria o privilégio cis. Para finalizar foi exibido um vídeo da música Mulher, da cantora Linn da Quebrada (2016).

Ato-limite 5: Construção da masculinidade. Foi exibido o documentário original Netflix: The Mask you live in (2015), que mostra como a masculinidade é um conceito construído culturalmente que transforma um menino em um homem.

Ato-limite 6: Orientação sexual: cura gay e banheiro unissex. Os dois temas foram debatidos com a finalidade de construção de conhecimento sobre o tema Orientação sexual.

Ato-limite 7: Aula síntese - biscoito sexual. Tendo em vista a construção de conhecimentos críticos, todos os temas trabalhados anteriormente foram imbricados nesta última atividade que trouxe o espectro da sexualidade humana em seus diferentes níveis. O objetivo da aula foi sintetizar as ideias construídas até aqui.

Ato-limite 8: Aula de aplicação do conhecimento. Com base nos conhecimentos construídos no decorrer das atividades, foi proposta a análise de revistas à procura de estereótipos de gênero e construção de cartazes ou panfletos a partir de recortes das figuras, para exposição em murais.

Com o processo de explicitação das visões de mundo ingênuas acerca das situações-limite em torno das questões de diversidade e diferença de gênero e sexualidade foram apresentados os atos-limite, em uma perspectiva de educação libertadora. A aposta é na educação libertadora como meio para a conscientização (FREIRE, 1987) dos(as) estudantes(as) como sujeitos críticos e ativos, no processo de transformação da realidade concreta desigual, injusta e opressora - o que vai ao encontro das ideias de Adorno e Horkheimer (1985) sobre a importância da dialética do esclarecimento, no contexto da indústria cultural e de processos de semi-formação dos sujeitos encarnados em uma sociedade capitalista. 


\section{Situações-limite e atos-limite em torno de questões sobre relações étnico-raciais}

As análises de situações-limite são discorridas considerando o percurso entre o ingresso de estudantes na licenciatura em Geografia e seus relatos na Prática de Ensino II (Estágio Supervisionado), no $8^{\circ}$ semestre, ao final da graduação, nos relatórios sobre a pesquisa desenvolvida no Quilombo do Cafundó. A intenção é refletir sobre como as(os) estudantes da licenciatura chegaram pensando as relações étnicas e raciais, neste momento em que carregam visões de mundo diversas, influenciadas não somente pela escola em que estudaram, mas pelas suas famílias e pelas ideologias presentes na sociedade. Ao discutir as questões de preconceito racial, entre as ideias que apareciam, nos chamava a atenção a predominância de que as relações raciais não pesam no vestibular e que é pelo mérito pessoal que a maioria estava lá (ressalte-se que a maioria de estudantes é formada por brancos), demonstra que as(os) estudantes estavam se baseando na ideia de meritocracia. Entendemos que, nessa discussão, aparece o tema gerador em torno da naturalização das desigualdades étnicas e raciais no Brasil. O enfrentamento das desigualdades étnicas e raciais podem ser vistas como contratema, ou seja, como a negação da meritocracia, pois elas estão presentes nas perspectivas do mercado de trabalho, escola, universidade $\mathrm{e}$, portanto, no acesso às universidades. Os não brancos ficam em desvantagem ao disputarem as oportunidades sociais, enquanto os mais brancos carregam o privilégio da brancura da pele e se situam melhor.

Outra situação-limite era a de que não há racismo no Brasil e de que eles mesmos não eram racistas. Apesar da diversidade de ordem étnico-racial, cultural, social, regional, existente no Brasil, o racismo não é aceito ainda como fundamento das relações sociais e interétnicas no país. Numa relação dialógica com a sala de aula, encontra-se um tema gerador: as identidades culturais negras e a identidade do negro, em geral, não são reconhecidas pelos "brancos" e, muitas vezes, também, pelos "não-brancos". Nesse sentido, refletir que, no Brasil, nega-se a existência do problema étnico ou de cor, aclamando-se, por muito tempo, a "democracia racial" destaca-se como contratema. Destacando-se ainda que essa crença possui uma força atuante, a qual tem o poder tanto de gerir as relações de cidadania quanto de propagar um falso pressuposto democrático com relação ao preconceito, à discriminação e, portanto, ao racismo.

Apareceu ainda como situação-limite o quilombo ter sido um fenômeno do passado, ter desaparecido após a Abolição, uma vez que não havia mais fugas tampouco escravidão no Brasil Moderno. Nessa concepção, a noção que 
prevalece é de que o território somente pode ser pensado a partir da presença do Estado e seu território, segundo a história da formação moderna dos Estados-Nação. No entanto, o conceito de território como uno e homogêneo seria central para desvelar as ideologias, sendo um tema gerador. A análise histórica da formação territorial brasileira foi um contratema fundamental para entender a invisibilidade das diferenças. A ideia do quilombo como um lugar de refúgio de escravos fugitivos faz parte da historiografia sobre a escravidão que o entende circunscrito ao período escravista e, por sua vez, entre os teóricos dos movimentos sociais que estudam o campo brasileiro a partir da categoria camponês. A discussão sobre a Questão Agrária Brasileira, ao tangenciar a questão das identidades e das diferenças em relação aos usos do território, por olhares micro e macroeconômicos, acaba por ver os camponeses, pequenos agricultores familiares e quilombolas como destinados a desaparecer sob a modernização do território. Por sua vez, segundo os olhares marxistas estruturalistas, os não brancos integrantes da estrutura do campo brasileiro seriam parte da comunidade camponesa, sendo ela sujeito da história.

Buscando problematizar as narrativas oficiais e ideológicas sobre a formação territorial, perguntava-se: se haveria outras narrativas, por que elas não são ouvidas num país multirracial? Quais as visões de outros atores sobre o território? Como são negociadas com as políticas governamentais?

Como ato-limite, lembramos que as Políticas Afirmativas têm sido implementadas nas universidades públicas federais, sendo que estudantes negras(os) autodeclaradas(os) passaram a ingressar pelo sistema de reserva de vagas. A presença de cotistas nas salas de aula, enquanto estudantes negras(os) autodeclaradas(os), qualificava o debate. Analisamos, também, que os movimentos sociais negros pressionaram os trabalhos da Constituinte de 1988, fazendo aprovar a legislação que reconhece a organização social e territorial quilombola e sua luta pelo território, como reparação social e reconhecimento da multiculturalidade brasileira e que é a partir dessas lutas que, cada vez um maior número de famílias se autodeclara quilombolas em todos os estados brasileiros (CARRIL, 1997). Em diversos espaços disciplinares, pudemos trabalhar com essas discussões que permearam o trabalho pedagógico: Educação, Política e Sociedade; Escola, Sociedade e Territórios; Geografia Crítica e Ensino; Prática de Ensino II (Estágio Supervisionado), com a Geografia, além de Metodologia das Práticas de Ensino em História e Geografia, na Licenciatura em Pedagogia.

Além da discussão teórica, desenvolvemos trabalhos de campo em 2 disciplinas: Prática de Ensino II (Estágio Supervisionado), na Licenciatura em Geografia e Metodologia de Prática e Ensino de História e Geografia (Licenciatura em Pedagogia), construindo projetos de estudo junto ao Quilombo do Cafundó. Em ambas as disciplinas, buscamos discutir as relações étnicas e raciais no espaço 
escolar, bem como a pedagogia crítica-freireana. Levamos em consideração, também, as exigências, normas e diretrizes do Ministério da Educação (MEC), os projetos buscaram a implementação da Lei 10.639/03 (BRASIL, 2003) "História e Cultura Afro-Brasileira" e de suas respectivas diretrizes curriculares nacionais, bem como a legislação que a substituiu - Lei 11.645/08 (BRASIL, 2008) - "História da África e a Cultura Afro-Brasileira e Indígena".

Ao analisarmos as ideologias geográficas, aparece, entre elas, a ideia geopolítica do Brasil Moderno, sua integração à natureza, seu povo oriundo da fusão de 3 raças em um único território, símbolos e signos que operam na representação da pátria, junto à bandeira, ao hino e às riquezas naturais (CHAUÍ, 2000). Assim, a construção de uma nação civilizada nos trópicos tinha, como projeto hegemônico, uma invenção do Brasil baseada numa metanarrativa geográfica, cujo território seria um todo coerente e estruturado pela própria natureza. Destacamos ainda que essa relação com o território é fruto da conquista colonial cuja herança subjaz às mentalidades e aos pactos forjados por suas elites herdeiras de significados conservadores do território que se formará. Segundo Moraes (2005), nunca fomos uma nação e não temos um território. As elites, articuladas ao capital internacional, historicamente, enxergam os fundos econômicos territoriais e não a nação e seu povo.

Dessa forma, a análise teórica e a visita de campo buscaram se articular a partir das reflexões e da exposição do processo histórico incluídas nos textos lidos e discutidos em aula com os participantes do trabalho, contribuindo para analisar o cenário. As(os) estudantes construíram o caderno de campo e a pesquisa sobre o território do Cafundó, a partir das observações, do registro das paisagens ao longo da viagem de saída da UFSCar até o Quilombo do Cafundó.

Para finalizar esta seção, apresentamos excertos extraídos dos Relatórios finais das(dos) estudantes contendo desdobramentos dos atos-limite, como parte das considerações finais do trabalho realizado no Quilombo do Cafundó, em 2016:

Assim, concluímos e entendemos as transformações que já ocorreram como consequência da luta da comunidade negra por seus direitos de igualdade e contra toda forma de preconceito, mas acreditamos que é necessária ainda a superação dessa história de marginalização das populações afrodescendentes através da aprendizagem entre brancos e negros, entre as trocas de conhecimento e as quebras de desconfiança. E acreditamos, além disso, no espaço da escola como possivel promoção e discussão dessas relações existentes entre culturas diferentes e as possibilidades de transformação de tal realidade (Estudante 1). 
A criação da linguagem da senzala cupópia é a resistência do povo negro escravizado que ainda existe graças ao sentido de pertencimento e de identidade dos seus descendentes, que lutaram contra as dificuldades para enfrentar os interesses econômicos, para a manutenção da terra de seus antepassados, da sua linguagem, ou seja, de sua cultura, em um movimento contra hegemônico de extrema dificuldade (Estudante 2).

Outro aspecto que trouxe surpresa a muitos de nós foi a presença de inúmeros moradores brancos, loiros e inclusive com olhos claros, pois, ao imaginar um quilombo, a grande maioria de nós imaginou uma grande maioria de pessoas negras, já que suas origens são africanas. Porém a miscigenação presente já nos periodos de escravidão e cada vez mais forte aqui no Brasil fez com que nascessem crianças cada vez mais miscigenadas, por isso, é possivel observar moradores negros, mulatos e brancos, mas todos de uma mesma cultura quilombola (Estudante 3).

\section{Considerações finais}

Neste trabalho, apresentamos práticas pedagógicas críticas construídas durante processos de formação inicial, buscando questionar o trabalho teórico desarticulado da prática. No contexto de um país ocidentalizado, cujo ideal branco e de tradição patriarcal, a teoria como prática libertadora implica abandonar o ensino e a transmissão de conhecimentos de forma bancária, cuja finalidade é reproduzir o status quo. Contudo, não se trata de pensar práticas centradas no docente, portador do conhecimento e vanguarda da produção de consciência no estudante, pois, como diz Freire (1987, p. 29): "Ninguém liberta ninguém, ninguém se liberta sozinho: os homens se libertam em comunhão".

A partir do conceito de situação-limite proposto por Freire (1987), trabalhamos com estudantes das licenciaturas em Biologia, Geografia e Pedagogia, em parceria com o PIBID e a Comunidade Quilombola Cafundó, em Salto de Pirapora - SP. Entendemos que as situações-limite são produzidas na vida social, tornando-se obstáculos históricos à desalienação, e se tornam dimensões desafiadoras de uma dada realidade. Contudo, posto que são processos produzidos em sociedade, nesse sentido, as situações-limite, como pensa Freire, podem ser superadas. A formação docente é um momento importante para trabalhar as contradições sociais presentes na realidade, que não são externas aos indivíduos, mas inerentes à sua própria constituição como sujeitos sociais. Essa imbricação indivíduo e sociedade mostra a complexidade do processo de 
superação das situações-limite, uma vez que a sociedade e suas contradições tendem a ser apresentadas aos(as) estudantes como algo naturalizado, fatalístico, imutável, de modo que os(as) estudantes venham a internalizar esses valores e reproduzir seus significados.

Dessa feita, a problemática centrada na produção da diferença e na compreensão de sua aparente exterioridade à dimensão da normalização social, e tomada como base do controle e hierarquização social, possibilitou o desvelamento da dinâmica ideológica presente nos esquemas de poder da sociedade capitalista. Juntamente às(aos) estudantes, constituiu-se trabalho profícuo à reflexão sobre a educação como prática de liberdade. Não se pretende afirmar que os professores não realizam a crítica necessária em outros momentos, e na própria prática, mas as etapas realizadas no PIBID e no Quilombo do Cafundó puderam refletir o "percebido destacado" (FREIRE, 1987), que é quando os sujeitos abrem distância do que os incomoda e os paralisa. A dialética, como movimento do pensamento junto à ação social, favorece o caminho da práxis transformadora, visto que compreendendo o problema, se demanda uma ação voltada para a sua superação.

Para tal, se faz necessário reconhecer as experiências de vida das(dos) estudantes, as situações-limite por eles trazidas e, de forma diretiva, construir atos-limite que lhes permitam se reconhecerem nos conhecimentos construídos na sala de aula. Num país multicultural, como o Brasil, as(os) educandas(os) devem ser convidadas(os) a conhecer a diversidade epistemológica num espaço criado pelo(a) educador(a) para incluir temas que tragam, por exemplo, consciência crítica de raça, sexo e classe associando-as à disciplina oferecida (HOOKS, 2013). Nesse sentido, é papel da escola/universidade desvelar visões de mundo acríticas (situações-limite), problematizá-las e criar possibilidades de superação dos obstáculos que impedem a emancipação (atos-limite), fazendo o sujeito voltar-se à transformação da realidade concreta, combatendo a reprodução de padrões culturais, comportamentais e atitudinais de caráter eurocêntricos, pautados pelos interesses da classe dominante do capital, que produz desigualdades, injustiças e violências, por exemplo, em torno das questões relativas à diferença.

Finalmente, a educação libertadora propicia vivificar o horizonte da democracia, ao permitir a visibilidade dos não brancos, das mulheres, dos LGBTQIA+ e das/dos marginalizadas(os), interferindo nas relações de poder presentes na educação via construção da consciência crítica para a ação crítica e transformadora no mundo. 


\section{REFERÊNCIAS}

ADORNO, Theodor W.; HORKHEIMER, Max. Dialética do Esclarecimento. Tradução de Guido Antônio de Almeida. Rio de Janeiro: Zahar Editores, 1985.

BENEVIDES, Bruna G.; NOGUEIRA, Sayonara Naider Bonfim (org.). Dossiê dos assassinatos e da violencia contra travestis e transexuais brasileiras em 2018. Brasília, DF: Distrito Drag: ANTRA: IBTE, 2019. Disponível em: https://antrabrasil.files. wordpress.com/2019/12/dossie-dos-assassinatos-e-violencia-contra-pessoas-transem-2018.pdf. Acesso em: 20 nov. 2019.

BRASIL. [Constituição (1988)]. Constituição da República Federativa do Brasil. Artigo 68 do Ato das Disposições Constitucionais Transitórias que estabelece: Aos remanescentes das comunidades dos quilombos que estejam ocupando suas terras é reconhecida a propriedade definitiva, devendo o Estado emitir-lhes os títulos respectivos. Brasília, DF: Senado Federal, 05 out. 1988. Disponível em: https:/www2.camara.leg.br/legin/fed/ conadc/1988/constituicao.adct-1988-5-outubro-1988-322234-publicacaooriginal-1-pl. html. Acesso em: 21 mar. 2000.

BRASIL. Presidência da República. Decreto n. 4.887, de 20 de novembro de 2003. Regulamenta o procedimento para identificação, reconhecimento, delimitação, demarcação e titulação das terras ocupadas por remanescentes das comunidades dos quilombos de que trata o art. 68 do Ato das Disposições Constitucionais Transitórias. Brasília, DF: Presidência da República, 21 nov. 2003. Disponível em: http://www.planalto. gov.br/ccivil_03/decreto/2003/d4887.htm. Acesso em: 08 abr. 2020.

BRASIL. Presidência da República. Lei $n^{\circ} 10.639$, de 09 de janeiro de 2003. Altera a Lei no 9.394, de 20 de dezembro de 1996, que estabelece as diretrizes e bases da educação nacional, para incluir no currículo oficial da Rede de Ensino a obrigatoriedade da temática "História e Cultura Afro-Brasileira". Brasília: DF, Presidência da República, 09 jan. 2003. Disponível em: http://www.planalto.gov.br/ccivil_03/leis/2003/110.639. htm. Acesso em: 10 jun. 2020.

BRASIL. Presidência da República. Lei $n^{\circ} 11.645$, de 10 de março de 2008. Altera a Lei no 9.394, de 20 de dezembro de 1996, modificada pela Lei no 10.639, de 9 de janeiro de 2003, que estabelece as diretrizes e bases da educação nacional, para incluir no currículo oficial da rede de ensino a obrigatoriedade da temática "História e Cultura Afro-Brasileira e Indígena”. Brasília: DF, Presidência da República, 11 mar. 2008. Disponível em: http://www.planalto.gov.br/ccivil_03/_ato2007-2010/2008/lei/111645. htm. Acesso em: 15 jun. 2020.

CARRIL, Lourdes de Fátima Bezerra. Territórios negros: comunidades remanescentes de quilombos no Brasil. AGB Informa, São Paulo, n. 67, p. 6-7, 1997.

CHAUÍ, Marilena. Brasil: Mito Fundador e Sociedade Autoritária. São Paulo: Editora Fundação Perseu Abramo, 2000. (Coleção História do Povo Brasileiro). 
CHIZZOTTI, Antônio. A pesquisa qualitativa em ciências humanas e sociais: evolução e desafios. Revista Portuguesa de Educação, Braga, Portugal, v. 16, n. 2, p. 221-236, 2003.

COSTA, Jurandyr Freire. Prefácio: Da cor ao corpo: a violência do racismo. In: SOUSA, Neusa Santos. Tornar-se negro e as vicissitudes da identidade do negro brasileiro em ascensão social. 2. ed. Rio de Janeiro: Edições Graal, 1990. p. 1-16.

CRENSHAW, Kimberlé. Documento para o encontro de especialistas em aspectos da discriminação racial relativos ao gênero. Estudos Feministas, Florianópolis, Ano 10, v. $1,2002$.

DELIZOICOV, Demétrio; ANGOTTI, José André; PERNAMBUCO, Marta Maria Castanho. de Almeida. Ensino de Ciências: Fundamentos e Métodos. São Paulo: Cortez, 2002. (Coleção Docência em Formação).

FOUCAULT, Michel. Nascimento da Biopolítica. Curso no Collège de France (19781979). São Paulo: Martins Fontes, 2008.

FOUCAULT, Michel. História da sexualidade I: A vontade de saber. 11. ed. Tradução de Maria Thereza da Costa Albuquerque. Revisão de José Augusto Guilhon Albuquerque. Rio de Janeiro: Graal, 1988.

FREIRE, Paulo. Pedagogia do Oprimido. 17. ed. Rio de Janeiro: Paz e Terra, 1987.

FREIRE, Paulo; SHOR, Ira. Medo e Ousadia: o cotidiano do professor. 5. ed. Rio de Janeiro: Paz e Terra, 1986.

HALL, Stuart. A identidade cultural na pós-modernidade. 7. ed. Rio de Janeiro: DP\&A, 2006.

HIRATA, Helena. Gênero, classe e raça, interseccionalidade e consubstancialidade das relações sociais. Tempo Social, São Paulo, v. 26, n. 1, p. 61-73, 2015.

HONNETH, Axel. Luta por reconhecimento: A gramática moral dos conflitos sociais. Tradução de Luiz Repa. São Paulo: Ed. 34, 2003.

HOOKS, Bell. A teoria como prática libertadora. In: HOOKS, Bell. Ensinando a transgredir: a educação como prática da liberdade. Tradução de Marcelo Brandão Cipolla. São Paulo: WMF Martins Fontes, 2013. p. 83-104.

LÜDKE, Menga; ANDRÉ, Marli Eliza Dalmazo Afonso. A Pesquisa em educação: abordagens qualitativas. São Paulo: EPU, 1986. (Temas básicos de educação e ensino).

LUZ, Rosa. Out of Drag-se com Rosa Luz | Barraco da Rosa/Rapper Trans. . [S.l.s.n.]. 2018. 1 vídeo (8 min $17 \mathrm{seg}$ ). Publicado pelo canal Youtube. Disponível em: https:// www.youtube.com/watch?v=FHJ83ROkg2Q. Acesso em: 30 nov. 2017.

MORAES, Antônio Carlos Robert. Território e História no Brasil. 2. ed. São Paulo: Annablume, 2005. 
PEREIRA, LINA (Linn da Quebrada). Mulher. [S.l.:s.n.]. 2016. 1 vídeo (6 min 41 seg). Publicado pelo Canal Youtube. Disponível em: https://www.youtube.com/ watch?v=J2L6QUiGeGo. Acesso em: 07 dez. 2017.

ROCHA, Cinthya Aparecida da. Gravidez na adolescência e evasão escolar. 2009. Trabalho de conclusão de curso (Licenciatura em Pedagogia) - Instituto de Biocências, Universidade Estadual Paulista, Rio Claro, 2009.

SAFATLE, Vladimir. Por Um Conceito "Antipredicativo" de Reconhecimento. São Paulo: Lua Nova, São Paulo, n. 94, p. 79-116, 2015.

SILVA, Antônio Fernando Gouvêa. A construção do currículo na perspectiva popular crítica: das falas significativas às práticas contextualizadas. 2004. Tese (Doutorado em Educação e Currículo). Pontifícia Universidade Católica, São Paulo. 2004.

SILVA, Tomás Tadeu da. A produção social da identidade e da diferença. In: SILVA, Tomás Tadeu da; HALL, Stuart; WOODWARD, Kathryn. Identidade e diferença: a perspectiva dos estudos culturais. 3. ed. Petrópolis, RJ: Vozes, 2004. p. 73-102.

THE MASK you live in. Direção de Jennifer Siebel Newson. Produção: Jennifer Siebel Newsom, Jessica Congdon, Jessica Anthony. [S.l.]: Netflix, 2015.

TRIVIÑOS, Augusto Nibaldo Silva. Introdução à pesquisa em ciências sociais. São Paulo: Atlas, 1987.

Texto recebido em $03 / 08 / 2020$.

Texto aprovado em 28/10/2020. 